\title{
Withdrawal from Genetic Counselling for Cancer
}

\author{
Eveline Bleiker', Gea Wigbout ${ }^{2}$, Anja van Rens' ${ }^{2}$, Senno Verhoef ${ }^{2}$, Laura van't Veer ${ }^{2}$, Neil Aaronson ${ }^{1}$ \\ IDivision of Psychosocial Research and Epidemiology, Netherlands Cancer Institute, Antoni van Leeuwenhoek Hospital, Amsterdam, the Netherlands; \\ 2Family Cancer Clinic, Netherlands Cancer Institute, Antoni van Leeuwenhoek Hospital, Amsterdam, the Netherlands
}

Key words: genetic counselling, breast cancer, non-participation, distress

Corresponding author: Eveline M.A. Bleiker, Division of Psychosocial Research and Epidemiology, Netherlands Cancer Institute, Plesmanlaan 121, 1066 CX Amsterdam, The Netherlands, phone +31 2051260 72, fax: +31 205122322 , e-mail: e.bleiker@nki.nl

Submitted: 31 January 2005

Accepted: 10 February 2005

\begin{abstract}
Background. A substantial minority of individuals who initially apply for genetic counselling for breast/ovarian cancer withdraw at an early stage from the counselling process. This study investigated the self-reported reasons for early withdrawal and the factors associated significantly with such withdrawal.

Methods. Self-report questionnaires were mailed to 83 women who had applied for genetic counselling for breast/ovarian cancer but who subsequently withdrew from the counselling process (the "withdrawers"). A comparison group of 105 women who had completed the genetic counselling (the "attendees") received a similar questionnaire. The questionnaire assessed sociodemographic characteristics, reasons for applying for genetic counselling, general distress (MHI-5), cancer-specific distress (IES), and cancer worries. For those women who discontinued the counselling, reasons for withdrawal were also assessed.

Results. The primary reasons given for withdrawing from counselling were difficulties in anticipating the consequences of genetic counselling (28\%), and worries about being unable to adequately cope with an unfavourable test result (20\%). Compared to the attendees, the withdrawers were significantly younger, more frequently asymptomatic, more often the first and only member of the family to apply for counselling, and less worried about cancer. Current levels of cancer-specific distress and general distress were comparable between the two groups.

Conclusion. Younger women, those without a history of cancer, and those who are first in their family to apply are more likely to withdraw prematurely from genetic counselling for breast/ovarian cancer. These withdrawers have no elevated levels of distress. However, a substantial percentage of individuals discontinue counselling due to concerns about their (in)ability to cope with a possible unfavourable test outcome. This suggests that greater attention should be paid to ways of coping with test results during the very first contact with the clinic.
\end{abstract}

\section{Introduction}

Localization of the two breast cancer susceptibility genes, BRCA1 and BRCA2, has enabled mutation detection techniques to be used for individuals who wish to learn whether or not they are at risk of being a mutation carrier [1,2]. While the majority of individuals who apply for genetic counselling and testing go forward with the procedure, a substantial minority do not follow through or withdraw from counselling at an early stage. For example, over a period of 4.5 years (from April 1995 to December 
Table 1. Sociodemographic and medical characteristics of the withdrawers $(n=48)$ and the attendees $(n=85)$

\begin{tabular}{|c|c|c|c|c|c|}
\hline & \multicolumn{2}{|c|}{ withdrawers $(n=48)$} & \multicolumn{2}{|c|}{ attendees $(n=85)$} & \multirow[t]{2}{*}{$\mathrm{p}$-value } \\
\hline & $n$ & $\%$ & $\mathrm{n}$ & $\%$ & \\
\hline Age (mean, sd) in years [range] & mean $=44[20-74]$ & $(s d=11)$ & mean $=50[26-78]$ & $(s d=12)$ & $p=0.003$ \\
\hline \multicolumn{6}{|l|}{ Marital status } \\
\hline - living with a partner/married & 37 & $77 \%$ & 62 & $73 \%$ & $p=0.60$ \\
\hline \multicolumn{6}{|l|}{ Children } \\
\hline- yes & 32 & $67 \%$ & 67 & $79 \%$ & $p=0.12$ \\
\hline \multicolumn{6}{|l|}{ Education } \\
\hline- low & 11 & $24 \%$ & 23 & $27 \%$ & \\
\hline - moderate & 16 & $35 \%$ & 39 & $46 \%$ & $p=0.20$ \\
\hline - high & 16 & $41 \%$ & 22 & $26 \%$ & \\
\hline \multicolumn{6}{|l|}{ Treated for cancer } \\
\hline- yes & 21 & $44 \%$ & 61 & $72 \%$ & $p=0.001$ \\
\hline \multicolumn{6}{|l|}{ Role in family } \\
\hline - first who applied & 41 & $85 \%$ & 35 & $41 \%$ & \\
\hline - first, with relative(s) & 2 & $4 \%$ & 38 & $45 \%$ & $p=0.000$ \\
\hline - others applied first & 5 & $10 \%$ & 12 & $14 \%$ & \\
\hline
\end{tabular}

1999), approximately 1,700 individuals contacted the Family Cancer Clinic of the Netherlands Cancer Institute and requested for genetic counselling. Of these 1,700 individuals, approximately two-thirds actually underwent genetic counselling, with or without genetic testing. However, the remaining one-third did not follow through with a clinic appointment.

The three most commonly reported reasons for initiating genetic counselling and/or testing for cancer are the desire to obtain a greater degree of certainty about personal cancer risk, to estimate the risk of cancer for one's children or other family members [3-7], and to obtain information on possible strategies for reducing the risk of developing cancer [6-8]. Other motives reported in the literature include family planning and a desire to contribute to scientific research $[3,4,7]$. It is unclear whether the initial motives of those who ultimately choose not to go forward with genetic counselling are different from those who actually do so.

Only a few studies have investigated the reasons why some individuals do not carry through after their initial application for genetic testing. Geer et al [9] reported that concerns about health insurance (41\%), cost of the genetic counselling and testing (32\%), the emotional impact of the process on oneself or one's family (30\%), low anticipated benefit (30\%), and time commitment $(24 \%)$ were the most frequently stated reasons for early withdrawal from genetic counselling for cancer. Other studies conducted in the U. S. confirm that concern about discrimination by health insurers plays a particularly important role in non-participation in genetic testing $[3,10]$, despite the fact that such fear is reported to greatly exceed actual discrimination practices [11]. Armstrong et al [12] found that those who declined genetic testing for cancer were less likely to consider it important to obtain information about their personal cancer risk or to provide such information to family members, and more frequently reported being concerned about consequences for health insurance than those who underwent testing.

Relatively little information is available on this subject from countries other than the U.S. In a recent study among 27 relatives from families in the UK with a known BRCA1/2 mutation who declined testing, the major barriers to testing included "apprehension about the result" (74\%), "travelling to the genetics clinic" (33\%) and "taking time away from work/family" (30\%) [13]. Additional issues that may negatively impact genetic clinic attendance include ambiguity in the invitation to attend the clinic, and dissatisfaction with the initial contact(s) with the clinic.

Studies of the possible association between levels of psychological distress and (non-)attendance or early withdrawal from genetic counselling and testing have yielded somewhat inconsistent results. In their study among women from families with a proven BRCA1/2 mutation, Lerman et al [14] found that the presence of cancer-related stress symptoms before genetic testing was strongly predictive of the onset of depressive symptoms in family members who were invited but declined testing. These non-attendees also experienced significantly higher levels of depression than women who 
Table 2. Most important reasons to request genetic counselling for the familial occurrence of breast/ovarian cancer: differences between the withdrawers $(n=48)$ and the attendees $(n=85)$

\begin{tabular}{|c|c|c|c|c|c|}
\hline & \multicolumn{2}{|c|}{ withdrawers } & \multicolumn{2}{|c|}{ attendees } & \multirow{2}{*}{$\frac{\chi^{2}}{\text { p-value }}$} \\
\hline & $\mathrm{n}$ & $\%$ & $n$ & $\%$ & \\
\hline to obtain certainty & 29 & 60 & 32 & 38 & 0.01 \\
\hline to be able to take preventive actions & 23 & 48 & 49 & 48 & 0.97 \\
\hline to estimate the risk for my children & 17 & 35 & 51 & 60 & 0.01 \\
\hline to help science & 6 & 13 & 10 & 12 & 0.90 \\
\hline worried about cancer (recurrence) & 12 & 25 & 24 & 28 & 0.69 \\
\hline requested by a family member & 3 & 6 & 19 & 22 & 0.02 \\
\hline referred by a physician & 11 & 23 & 11 & 13 & 0.14 \\
\hline general planning for the future & 2 & 4 & 0 & - & {$[0.06]$} \\
\hline family planning & 1 & 2 & 4 & 5 & 0.45 \\
\hline
\end{tabular}

had gone forward with testing (regardless of the test results). A recent small Dutch study [15] described attitudes and distress levels among 13 women at 25\% or $50 \%$ risk of being a BRCAl/2 mutation carrier, who declined genetic testing. Four women (31\%) reported feeling emotionally unprepared to cope with the consequences of testing; however, no significant differences were found in mean distress levels between these women and a comparison group composed of women who had undergone genetic testing. Valdimarsdottir et al [16] reported that women with a previous history of breast cancer who had high or low levels of anxiety declined genetic counselling more frequently than women with intermediate levels of anxiety. Foster et al [13] reported that female test decliners had significantly lower levels of cancer worries than the female test acceptors. Other studies have also reported a positive relationship between cancer-specific distress and participation in BRCAl/2 counselling and/or testing (i.e. higher participation rates among those with higher levels of cancer-specific distress) $[17,18]$.

A final factor that may play a role in early withdrawal from genetic counselling is the timing of an individual's contact with the clinic in relation to that of other family members. That is, those who are the first in their family to undergo genetic counselling may have a more difficult task than those who request genetic counselling after other family members have completed the process [19]. One could also hypothesize that the "first utilizers" of genetic counselling in a family may be those who are more likely to withdraw early from the process due to family-related stress. There are currently no empirical data available to inform on this latter issue.
The present study was undertaken to investigate the self-reported reasons for early withdrawal from cancer genetic counselling/testing in the Dutch setting, and to determine which sociodemographic, clinical and psychosocial factors are significantly associated with such withdrawal.

\section{Methods}

\section{Study setting and standard clinic procedures}

The study was conducted at the Family Cancer Clinic of the Netherlands Cancer Institute in Amsterdam, the Netherlands. At this clinic, individuals requesting genetic counselling typically do so initially by telephone. A brief risk assessment is made by the genetic nurse to determine the appropriateness of the request. If applicable, individuals then receive a "family form" to be completed before the first visit to the clinic. The purpose of this form is to obtain a full description of the cancer history of all first degree, second degree and, if possible, third degree family members. During the initial face-to-face intake session at the clinic, a family tree is drawn and information is provided about the possibilities and limitations of genetic testing. Between 6 weeks and 3 months following this initial visit (once medical data on relatives have been obtained, and diagnoses confirmed) a second consultation takes place at the clinic during which details of the family are discussed, and the attitude of the counselee (and his/her partner) towards genetic testing is explored. DNA testing is then offered, when appropriate. The results of the 
Table 3. Most important reasons given for withdrawal from genetic counselling by the group of non-attendees ( $n=46$ )

\begin{tabular}{|c|c|c|}
\hline & $\mathrm{n}$ & $\%$ \\
\hline It is difficult to anticipate the consequences of genetic counselling & 13 & 28 \\
\hline I am worried that I will not cope well with an unfavourable test result & 9 & 20 \\
\hline I do not have sufficient information about cancer in my family & 9 & 20 \\
\hline I want to postpone the genetic counselling for some years & 9 & 20 \\
\hline I am worried that genetic counselling may cause stress in my immediate relationship/family (partner/children) & 8 & 17 \\
\hline I am not interested in genetic counselling at the moment, it has low priority & 6 & 13 \\
\hline The subject "cancer and hereditary" is too emotional/burdensome & 6 & 13 \\
\hline One or more relatives do not want to participate in the genetic inquiries/counselling & 4 & 9 \\
\hline I am worried about possible consequences for obtaining a mortgage or life insurance & 4 & 9 \\
\hline I am worried that genetic counselling may cause stress within my larger family (brothers/sisters/cousins/parents, etc.) & 4 & 9 \\
\hline I am worried about the possible consequences for my future plans (starting a relationship, choice of job, wish for children) & 4 & 9 \\
\hline I am still waiting for an invitation from the family cancer clinic & 3 & 7 \\
\hline I do not expect that genetic counselling will bring much news for me & 2 & 4 \\
\hline I will wait for the results from other family members before I proceed with genetic counselling & 1 & 2 \\
\hline Others advised me against the genetic counselling & 1 & 2 \\
\hline I have had bad experiences with the family cancer clinic & 0 & 0 \\
\hline
\end{tabular}

DNA testing are made available between 6 weeks (in those cases where a gene mutation in the family is already known) and approximately 6 months after the blood sample is taken. The results are conveyed to the counselee(s) in a face-to-face consultation. The counselling program is described in great detail elsewhere [4].

\section{Study sample and procedures}

The study sample comprised two groups: (1) women who requested genetic counselling for breast and/or ovarian cancer but ultimately did not carry through with the process (hereafter referred to as "withdrawers"); and (2) women who, during the same period, requested genetic counselling for breast and/or ovarian cancer and completed the counselling process.

The "withdrawer" sample. The withdrawer sample was composed of women who requested genetic counselling for breast/ovarian cancer at the Family Cancer Clinic of the Netherlands Cancer Institute between January 1999 and March 2000, who either had a telephone contact with the clinic but did not follow through with a clinic appointment, or had attended once but had not returned for a second session during the subsequent 12-month period.

All eligible women received a self-report questionnaire, on average, 18 months (median 17, SD 4 months) after their application for genetic counselling. Those who had not responded to the questionnaire within 3 weeks were sent a reminder letter together with a copy of the questionnaire.

The "attendee" sample. A comparison group was composed of women who had initiated genetic counselling at the same clinic during the same time period as the withdrawer group, but had subsequently completed the counselling process. These women were participating in a parallel study of the psychosocial impact of genetic counselling. They completed a self-report questionnaire approximately one month after their final appointment at the clinic; this was, on average, 8 months (median 7, SD 5 months) after their first visit to the clinic. Those women who had not responded to this questionnaire within 3 weeks were sent a reminder letter together with a copy of the questionnaire. The study was approved by the institutional review board of the hospital. 


\section{Questionnaire content}

Sociodemographic and medical variables included age, education, marital status, number of children, previous history of cancer, role in the family with regard to genetic counselling (i.e. first and only applicant; first applicant together with other family members; secondary applicant).

Reasons for seeking genetic counselling: Based on previous studies $[4,20]$ a list of possible reasons for undergoing genetic counselling was presented. Respondents were asked to indicate the 3 most important reasons why they had sought counselling.

General distress, cancer-specific distress, and cancer worries: General psychological distress was assessed with the Mental Health Index-5 (MHI-5), a subscale of the SF-36 Health Survey [21, 22]. Cancer-specific distress was assessed with the subscale "intrusive thoughts" of the Impact of Event scale (IES) $[23,24]$. In the present study, the questions focused on the extent of intrusive thoughts about the familial occurrence of cancer. The IES has been used previously in the context of genetic counselling [14,25]. Cancer worries were assessed with an adapted version of the 4 -item cancer-worry scale of Lerman et al [26]. This scale assesses the frequency of worries during the previous 4-week period about one's own cancer risk and the risk of cancer among family members, and the impact of such worries on mood, and daily functioning.

Reasons for withdrawing from the genetic counselling: Those women who had withdrawn from the genetic counselling process were asked to select from a pre-set list those factors that had played a part in their decision to withdraw. They could also add additional reasons not included in the list (for the items, see Table 3).

Intention to continue genetic counselling was assessed with a single question: "Do you intend to continue genetic counselling at some time in the future?" The response categories were adapted from those used by Jacobsen et al [27]: 1) no, certainly not; 2) no, not yet; 3) yes, sometime in the future (after more than one year); 4) yes, within one year; 5) yes, I have just continued; or 6) I don't know.

\section{Statistical analysis}

Student's t-tests and chi-square tests were used to make comparisons between the withdrawers and attendees at the univariate level. Logistic regression analysis was used to identify those variables most strongly associated with (non-)participation in the genetic counselling at the multivariate level.

\section{Results}

\section{Response rates}

Response of the withdrawal sample: In total, 83 women were identified as being withdrawers. However, 10 of the women were subsequently excluded from the study sample for the following reasons: 5 women reported that they had continued counselling in another clinic; 2 women learned that their sister, who had undergone genetic counselling, had received an inconclusive test result and consequently genetic testing was no longer indicated; 1 woman was told at intake that she was at low risk and therefore counselling was not necessary; 1 woman died; and 1 woman moved to an unknown address. Of the remaining 73 eligible women, $48(66 \%)$ returned the questionnaire. Of these 48 respondents, 36 had had a telephone intake only and 12 had participated in one face-to-face intake; none had had any further contact with the clinic for at least 12 months following their initial contact.

Response of the attendees: In total, 105 women who completed their genetic counselling for breast and/or ovarian cancer were invited to participate in the study. Of these, 85 women (81\%) completed and returned the questionnaire. Of these 85 women, 15 were found to be a carrier of a BRCA1/2 mutation, 6 were proven to be a non-carrier, and the remainder had an inconclusive DNA test result $(n=62)$ or did not undergo DNA testing $(n=2)$.

\section{Sociodemographic and clinical characteristics of withdrawers versus attendees}

Compared with the attendees, the withdrawers were significantly younger (mean $=44$ vs. 50 years; $p=0.003$ ), more frequently asymptomatic ( $44 \%$ vs. $61 \% ; p=0.001)$, and more frequently the first and sole individual in their family to have applied for genetic counselling (85\% vs. $41 \% ; p<0.000$ ) (Table 1). No statistically significant differences were found between the two groups for education, marital status, or having children.

\section{Self-reported reasons for requesting genetic counselling}

Both the withdrawer and attendee groups indicated that three most important reasons to undergo the genetic counselling were to obtain certainty, to be able to take preventive actions, and to estimate the cancer risk for their children (Table 2). However, the withdrawers were more likely to report obtaining certainty for themselves as the primary reason for seeking counselling $(60 \%$ vs. $38 \%, p=0.01)$, whereas the attendees 
Table 4. Data on general distress (MHI-5), cancer-specific distress (IES), and cancer worries

\begin{tabular}{|c|c|c|c|c|c|c|c|}
\hline & With & ers $(n=$ & & Atte & $(n=8$ & & $\mathrm{p}$-value \\
\hline & Mean (sd) & $n$ & $\%$ & Mean (sd) & $\mathrm{n}$ & $\%$ & \\
\hline General distress (MHI-5)* & $74(15)$ & & & $72(15)$ & & & $p=0.39$ \\
\hline$-\operatorname{low}(\leq 59)$ & & 7 & $15 \%$ & & 17 & $21 \%$ & \\
\hline - moderate $(60-80)$ & & 24 & $51 \%$ & & 39 & $48 \%$ & $p=0.71$ \\
\hline$-\operatorname{high}(\geq 81)$ & & 16 & $34 \%$ & & 26 & $32 \%$ & \\
\hline Cancer-specific distress (IES)** & $7.8(7.5)$ & & & $10.2(8.4)$ & & & $p=0.12$ \\
\hline$-\operatorname{low}(\leq 8)$ & & 25 & $58 \%$ & & 34 & $45 \%$ & \\
\hline - moderate (9-19) & & 13 & $30 \%$ & & 30 & $40 \%$ & $p=0.37$ \\
\hline$-\operatorname{high}(\geq 20)$ & & 5 & $12 \%$ & & 12 & $16 \%$ & \\
\hline Cancer worries** & $5.9(2.1)$ & & & $7.3(2.2)$ & & & $p<0.000$ \\
\hline - few/none $(\geq 5)$ & & 30 & $64 \%$ & & 18 & $23 \%$ & \\
\hline - some (6-8) & & 10 & $21 \%$ & & 38 & $49 \%$ & $p<0.000$ \\
\hline - frequently $(\geq 9)$ & & 7 & $15 \%$ & & 22 & $28 \%$ & \\
\hline
\end{tabular}

* high scores indicate low distress (or high mental health)

** high scores indicate high distress

indicated estimating the risk for their children most frequently $(60 \%$ vs. $35 \%, p=0.01)$. Approximately one-quarter of the respondents in both groups indicated that being worried about cancer (recurrence) was a major reason for seeking counselling. Those who withdrew from counselling were significantly less likely to have attended the clinic upon request of a family member than were those who continued with the counselling process (6\% vs. $22 \%, p=0.02)$.

\section{Self-reported reasons for withdrawing from genetic counselling}

Of the women who withdrew from genetic counselling $28 \%$ indicated that they found it difficult to anticipate the consequences of the counselling, 20\% were worried that they could not handle an unfavourable genetic test result, and $20 \%$ believed that they had insufficient information about the occurrence of cancer in their family to merit continued counselling (Table 3). 17\% of the respondents were worried that the genetic counselling might cause stress in their relationship with their partner or children, and $9 \%$ were worried about such problems with their extended family (parents, brothers, sisters, cousins, etc.). Another 9\% were worried about possible discrimination in obtaining a mortgage or life insurance, and $9 \%$ were concerned about the possible consequences for future plans such as starting a relationship, starting a family, or pursuing a career. None of the women reported dissatisfaction with the quality of the genetic counselling service as a reason for withdrawing. Interestingly, 3 women indicated that they had not continued the counselling because they were still waiting for an invitation from the clinic to do so (after more than 1 year).

Of the 48 women who withdrew, $48 \%$ planned to continue the genetic counselling in the future: 4 women had recently made an appointment with the clinic, 10 intended to make an appointment within 1 year, and 9 planned to make an appointment sometime in the future. Only 1 woman was convinced that she did not want further counselling, 3 had no definite plans, and 14 were undecided. Seven women gave other answers such as: "I would like to discuss this with my physician before taking any steps"; "I would like to continue the counselling, but only if I don't have to complete the family history form".

\section{Current levels of psychological distress}

There were no statistically significant differences between the withdrawers and the attendees in the mean scores for general distress (MHI-5). Moreover, the mean scores of both groups were comparable to normative data of Dutch women from the general population (aged 20-78 years) [22]. 
No statistically significant differences were observed between withdrawers and attendees in mean levels of intrusive thoughts (IES scores), or in the percentage with clinically relevant levels of such thoughts (scores $>20 ; 12 \%$ vs. $16 \%, p=0.37$ ).

Women from the withdrawer group experienced, on average, significantly fewer worries about cancer during the previous 4 weeks compared with the attendees $(p<0.001)$ (Table 4). This was evidenced both when analysing cancer worries as a continuous variable, and when categorizing the scale into "few/none" versus "some" versus "frequent" worries.

\section{Discussion}

This study was undertaken to investigate the selfreported reasons for discontinuation of the genetic counselling process for breast/ovarian cancer, and to determine which factors are significantly associated with such withdrawal. The results suggest that those women who withdraw from genetic counselling are more likely to have applied for counselling out of concern about their own cancer risk, rather than that of their children. A similar finding has been reported earlier [12]. Conversely, those who continued counselling were more likely to have had cancer, and thus may have been less concerned about their own cancer risk than that of their children or other family members. Social network influences also appear to play a role in the decision to (dis)continue genetic counselling, as those who withdrew from the process were less likely than those who continued to have been prompted by family members to seek counselling in the first place.

Although the self-reported reasons for early discontinuation of genetic counselling were diverse, the main reasons cited were of a psychosocial nature, including difficulties in anticipating the consequences of genetic counselling, worries about not being able to cope well with an unfavourable test result, and concerns that the counselling process might create stress in the family. As also reported by Lodder et al [15], most withdrawers seemed to have thoroughly reflected on their own decision not to undergo genetic counselling. In contrast to studies emanating from the U.S. [3, 10, 11], relatively few women indicated that fear of insurance or job discrimination contributed significantly to their decision not to go forward with genetic counselling and testing.

We were concerned that those who withdrew prematurely from the counselling process might report high levels of distress at follow-up. However, this was not found to be the case. Current levels of both general and cancer-specific distress were comparable to those who continued with the counselling. Moreover, withdrawers reported significantly fewer cancer worries than the attendees. Similar findings have been reported by Foster et al [13].

Several possible limitations of the study merit mentioning. First, although the overall response rate of $75 \%$ is quite respectable for this type of survey research, higher levels of non-response were observed in the withdrawer group than in the attendee group (66\% vs. $81 \%$ ). One cannot rule out the possibility that those women who chose not to complete our survey may have differed from the participants in their selfreported motives for initiating genetic counselling, and in their current levels of psychological distress. We would also note that our study sample was restricted to those women who had sufficient interest, at least initially, in genetic counselling to contact the family cancer clinic. The results cannot be generalized to the broader population of high-risk women who have never had contact with a family cancer clinic. This is a separate but important population of women that deserves additional research attention.

Given the cross-sectional retrospective study design, it was not possible to determine whether levels of psychological distress at the time of the initial contact with the family cancer clinic were associated significantly with the decision to withdraw from the counselling process. We would emphasize that our results regarding current levels of psychological distress cannot be compared with those reported by Lerman et al [14] and Valdimarsddottir et al [16] in that, in these latter studies, distress levels were assessed prior to the decision to continue or discontinue counselling.

Finally, we would note that our data are based primarily on self-reported attitudes and behaviour. Thus, for example, we assessed the behavioural intentions of those women who had withdrawn from counselling. Interestingly, of the 23 withdrawers who indicated that they intended to restart the genetic counselling at some later date, only 8 had done so at the time that this report was being written (approximately 3 years later). This would suggest that the withdrawals that we observed most often reflected a final decision, rather than postponement of counselling.

\section{Clinical relevance of the study}

The primary objective of this study was to better understand the reasons why clients withdraw prematurely from genetic counselling, and to determine if such withdrawal is related significantly to the sociodemographic, psychosocial or clinical characteristics of the individual, or to factors related to the counselling services themselves.

The results suggest that there is little reason to be concerned about heightened levels of psychological 
distress among early withdrawers. Levels of selfreported distress were comparable between the withdrawer and attendee groups, and the withdrawers actually reported significantly fewer cancer worries than the attendees. Nevertheless, we would note that concerns about not being able to anticipate the consequences of genetic counselling and worries about not being able to cope well with an unfavourable DNA test result were important self-reported reasons for discontinuing the counselling. This suggests the need to devote greater attention early in the counselling process to discussing both the possible consequences of the counselling process and outcome, and in evaluating individual client's concerns about their ability to cope with negative outcomes.

The results also suggest that younger attendees, those without a history of breast cancer, and those who are the first in their family to request genetic counselling are at greatest risk of early withdrawal. Previous studies have demonstrated the value of shared responsibility within families seeking genetic counselling [19], and thus it may be important to encourage individuals who apply for such counselling to engage other family members in the process. Finally, we observed that the majority of those who withdraw from the counselling did so following an initial telephone contact, but before they had had a face-to-face information/education session during which the nature and possible consequences of genetic counselling could be discussed in greater detail. We would recommend that clinic intake procedures be designed in such a way that encourage deferring the decision about whether or not to go forward with counselling and testing until such a face-to-face session has taken place. In this way, potential clients will be in a better position to make a more informed and balanced decision about whether to continue to receive counselling and potentially to undergo genetic testing, and whether this might be appropriate for other family members as well.

\section{Acknowledgment}

Dr Bleiker received financial support from the Dutch Cancer Society (NKI 2003-2977) in carrying out this study.

\section{References}

1. Miki Y, Swensen J, Shattuck-Eidens D, Futreal PA, Harshman K, Tavtigian S, Liu Q, Cochran C, Bennett LM, Ding W, Bell R, Rosenthal J, Hussey C, Thanh T, McClure M, Frye C, Hattier T, Phelps R, Haugen-Strano A, Katcher H, Yakumo K, Gholami Z, Shaffer D, Stone S, Bayer S, Waray C, Bogden R, Dayananth P, Ward J, Tonin P, Narod S, Bristow P, Norris F, Helvering L, Morrison P, Rosteck P, Lai M, Barrett JC, Lewis C, Neuhausen S, CannonAlbright L, Goldgar D, Wiseman R, Kamb A and Skolnick M. A strong candidate for the breast and ovarian cancer susceptibility gene BRCA1. Science 1994; 266 (5182): 66-71.
2. Wooster R, Bignell G, Lancaster J, Swift S, Seal S, Mangion J, Collins N, Gregory S, Gumbs C and Micklem G. Identification of the breast cancer susceptibility gene BRCA2. Nature 1995; 378 (6559): 789-792.

3. Lynch HT, Watson P, Tinley S, Snyder C, Durham C, Lynch J, Kirnarsky Y, Serova O, Lenoir G, Lerman C and Narod SA. An update on DNA-based BRCA1/BRCA2 genetic counseling in hereditary breast cancer. Cancer Genet Cytogenet 1999; 109 (2): 91-98.

4. Bleiker EM, Aaronson NK, Menko FH, Hahn DE, van Asperen CJ, Rutgers EJ, ten Kate LP and Leschot NJ. Genetic counseling for hereditary cancer: a pilot study on experiences of patients and family members. Patient Educ Couns 1997; 32 (1-2): 107-1 16.

5. Brain K, Gray J, Norman P, Parsons E, Clarke A, Rogers C, Mansel R and Harper P. Why do women attend familial breast cancer clinics? J Med Genet 2000; 37 (3): 197-202.

6. Brandt R, Hartmann E, Ali Z, Tucci R and Gilman P. Motivations and concerns of women considering genetic testing for breast cancer: a comparison between affected and at-risk probands. Genet Test 2002; 6 (3): 203-205.

7. Lerman C, Seay J, Balshem A and Audrain J. Interest in genetic testing among first-degree relatives of breast cancer patients. Am J Med Genet 1995; 57 (3): 385-392.

8. Lerman C, Narod S, Schulman K, Hughes C, Gomez-Caminero A, Bonney G, Gold K, Trock B, Main D, Lynch J, Fulmore C, Snyder $C$, Lemon SJ, Conway T, Tonin P, Lenoir $G$ and Lynch $H$. BRCA1 testing in families with hereditary breast-ovarian cancer. A prospective study of patient decision making and outcomes. JAMA 1996; 275 (24): 1885-1892.

9. Geer KP, Ropka ME, Cohn WF, Jones SM and Miesfeldt S. Factors influencing patients' decisions to decline cancer genetic counseling services. J Genet Couns 2001; 10 (1): 25-40.

10. Peterson EA, Milliron KJ, Lewis KE, Goold SD and Merajver SD. Health insurance and discrimination concerns and BRCA1/2 testing in a clinic population. Cancer Epidemiol Biomarkers Prev 2002; 11 (1): 79-87.

11. Hall MA and Rich SS. Patients' fear of genetic discrimination by health insurers: the impact of legal protections. Genet Med 2000; 2 (4): 214-221.

12. Armstrong K, Calzone K, Stopfer J, Fitzgerald G, Coyne J and Weber B. Factors associated with decisions about clinical BRCA1/2 testing. Cancer Epidemiol Biomarkers Prev 2000; 9 (11): 1251-1254.

13. Foster C, Evans DGR, Eeles R, Eccles D, Ashley S, Brooks L, Cole T, Cook J, Davidson R, Gregory H, Mackay J, Morrison PJ and Watson M. Non-uptake of predictive genetic testing for BRCA1/2: attributes, cancer worry, and barriers to testing in a multi-centre clinical cohort. Genet Test 2004; 8 (1): 23-29.

14. Lerman C, Hughes C, Lemon SJ, Main D, Snyder C, Durham C, Narod $S$ and Lynch HT. What you don't know can hurt you: adverse psychologic effects in members of BRCA 1 -linked and BRCA2-linked families who decline genetic testing. J Clin Oncol 1998; 16 (5): 1650-1654.

15. Lodder L, Frets PG, Triisburg RW, Kliin JG, Seynaeve C, Tilanus MM, Bartels CC, Meijers-Heiiboer EJ, Verhoog LC and Niermeijer MF. Attitudes and distress levels in women at risk to carry a BRCA1/BRCA2 gene mutation who decline genetic testing. Am J Med Genet 2003; 119A (3): 266-272.

16. Valdimarsdottir HB, Bovbjerg DH, Brown K, Jacobsen P, Schwartz MD, Bleiker E, Offit K, Borgen P, Heerdt A and van Zee K. Cancer-specific distress is related to women's decisions to undergo BCRA1-testing. Cancer Res Ther Control 1999; 8: 61-68.

17. Lerman $C$, Schwartz MD, Lin TH, Hughes $C$, Narod S and Lynch $H T$. The influence of psychological distress on use of genetic testing for cancer risk. J Consult Clin Psychol 1997; 65 (3): 414-420. 
18. Thompson HS, Valdimarsdottir HB, Duteau-Buck C, Guevarra J, Bovbjerg DH, Richmond-Avellaneda C, Amarel D, Godfrey D, Brown $\mathrm{K}$ and Offit $\mathrm{K}$. Psychosocial predictors of BRCA counseling and testing decisions among urban African-American women. Cancer Epidemiol Biomarkers Prev 2002; 11 (12): 1579-1585.

19. DudokdeWit AC, Tibben A, Frets PG, Meijers-Heijboer EJ, Devilee P, Klijn JG, Oosterwijk JC and Niermeijer MF. BRCA1 in the family: a case description of the psychological implications. Am J Med Genet 1997; 71 (1): 63-71.

20. Tibben A, Frets PG, van de Kamp JJ, Niermeijer MF, Vegter-van der Vlis M, Roos RA, van Ommen GJ, Duivenvoorden HJ and Verhage F. Presymptomatic DNA-testing for Huntington disease: pretest attitudes and expectations of applicants and their partners in the Dutch program. Am J Med Genet 1993; 48 (1): 10-16.

21. Ware JE, Snow KK, Kosinski M and Gandek B. SF-36 Health Survey: Manual and Interpretation Guide. Boston, M. A. New England Medical Center, The Health Institute, 1993.

22. Aaronson NK, Muller M, Cohen PD, Essink-Bot ML, Fekkes M, Sanderman R, Sprangers MA, te Velde A and Verrips E. Translation, validation, and norming of the Dutch language version of the SF36 Health Survey in community and chronic disease populations. J Clin Epidemiol 1998; 51 (11): 1055-1068.

23. Horowitz M, Wilner $\mathrm{N}$ and Alvarez W. Impact of Event Scale: a measure of subjective stress. Psychosom Med 1979; 41 (3): 209-218.

24. Brom D and Kleber RJ. De schok verwerkingslijst [Impact of Event Scale]. Ned Tijdschr Psychol 1985; 40: 164-168.

25. Valdimarsdottir HB, Bovbjerg DH, Kash KM, Holland JC, Osborne MP and Miller DG. Psychological distress in women with a familial risk of breast cancer. Psycho-oncology 1995; 4: 133-141.

26. Lerman C, Daly M, Masny A and Balshem A. Attitudes about genetic testing for breast-ovarian cancer susceptibility. J Clin Oncol 1994; 12 (4): 843-850.

27. Jacobsen PB, Valdimarsdottir HB, Brown KL and Offit K. Decision-making about genetic testing among women at familial risk for breast cancer. Psychosom Med 1997; 59 (5): 459-466. 